acid-base homeostasis ammonium

bicarbonate

infants
$\mathrm{pH}$

phosphaturia

respiratory distress syndrome

\title{
Renal Acid Excretion in Infants with the Respiratory Distress Syndrome
}

\author{
Alexander G. Allen ${ }^{[41]}$, and Robert Usher \\ Departments of Obstetrics and Paediatrics, Royal Victoria Hospital and McGill University, Montreal, Canada
}

\section{Extract}

Acid-base balance in blood and hydrogen ion, phosphorus concentrations, and acidbase excretion in urine were measured in 10 infants with respiratory distress syndrome (RDS), in 8 control full term infants, and in 7 control premature infants on days 1, 2, and 3 of life. Infants with RDS were acidemic in comparison with full term and premature control infants.

Hydrogen ion concentrations in urine were similar for premature control subjects and acidemic infants with RDS but lower in comparison with those of full term control infants. The inability of infants with RDS, in the face of acidemia, to create an appreciable urine to plasma hydrogen ion concentration gradient provided evidence for a renal tubular deficiency in hydrogen ion secretion.

Phosphate levels in urine and, as a result, titratable acid were usually low in the three groups of infants. Relative phosphaturia did occur in some infants with RDS, but, because of the deficiency in hydrogen ion secretion, urinary phosphate was often not utilized as titratable acid.

At high urinary concentrations of hydrogen ion (above $400 \mu \mathrm{mEq} / \mathrm{liter}$ ), control premature infants and acidemic infants with RDS excreted urine having lower ammonium concentration than that found in control full term infants. The inability of infants with RDS with acidemia to excrete ammonium when hydrogen ion concentrations in urine were high was evidence of a renal tubular deficiency in ammonia production.

Infants with RDS differed from control premature infants by having high hydrogen ion and bicarbonate concentrations in blood in relation to higher blood $\mathrm{PCO}_{2}$ values. In addition, at low hydrogen ion concentrations in urine, infants with RDS excreted urine that contained higher concentrations of bicarbonate than that found in control premature infants.

Because infants with RDS did not excrete ammonium, they could not compensate for the increased acid load and bicarbonate excretion associated with respiratory acidemia. In addition, they could not compensate for the low titratable acid, which resulted from decreased excretion of phosphate, characteristic of the newborn period.

Infants with RDS did not respond to acidemia by increasing net acid excretion in urine beyond that excreted by control infants. Indeed, some infants with RDS inappropriately excreted base, thereby aggravating their already existing acidemia.

\section{Speculation}

Low gestational and postnatal age is the likely etiologic factor responsible for the decreased capacity for urinary acid excretion seen in infants with RDS. The apparent 
improvement in renal tubular hydrogen ion secretion with increasing gestational age may be associated with maturation of an enzyme system such as carbonic anhydrase. Likewise, the apparent improvement in renal tubular ammonia production with increasing gestational age may occur in relation to maturation of an enzyme system such as glutaminase.

\section{Introduction}

Respiratory distress syndrome of prematurity is commonly associated with combined respiratory and metabolic acidosis which often persists during week 1 of life [32]. The severity and duration of this acidosis has been shown to be inversely related to prognosis for survival $[5,32]$.

Renal excretion of acid is an important means for aclieving acid-base homeostasis. Persistence of respiratory acidosis without an appreciable increase in extracellular bicarbonate concentration for 3 or more days [32] suggests that the renal capacity for acid excretion in these infants is impaired. Hatemi and McCance [12] have shown that normal full term infants at 1 week of age took longer than adults to excrete a comparable metabolic acid load. There is at present no information on the ability of premature infants to excrete acid in urine during week 1 of life. The present investigation was undertaken to compare acid excretion in urine in premature infants in response to acidosis associated with RDS with that in healthy, nonacidemic premature and full term infants.

\section{Subjects}

Ten infants with RDS, eight healthy full term controi infants, and seven nondistressed premature control infants were studied during the first 3 days of life. The birth weight and gestational age of each infant are given in Table $\mathrm{I}$. All full term control infants weighed $2960 \mathrm{~g}$ or more and all premature control infants weighed $1950 \mathrm{~g}$ or less. Two full term infants (nos. 1 and 5), whose gestational ages were unknown, had clinical criteria [34] for a gestational age of 40 weeks. Eight of the 10 infants with RDS weighed $2300 \mathrm{~g}$ or less. Two infants with RDS (nos. 18 and 24), both of whom were infants of diabetic mothers, weighed 3500 and $4710 \mathrm{~g}$ at gestational ages of 34.5 and 37.5 weeks, respectively. One infant with RDS (no. 23) whose gestational age was unknown had the clinical criteria [34] for a gestational age of 34 weeks.

Respiratory distress syndrome was diagnosed clinically when an infant lad expiratory grunting, subcos- tal retractions, and decreased breath sounds on auscultation persisting beyond the first $3 \mathrm{hr}$ of life. All 10 infants with RDS had a clinical course which lasted 2-3 days. Two infants with RDS (nos. 16 and 25) had Apgar scores below 6 at 1 min of age. Three infants died, no. 18 at $34 \mathrm{hr}, n o .24$ at $33 \mathrm{hr}$, and no. 25 at 13 hr of age, and at autopsy were found to have had hyaline membrane disease. One infant with RDS (no. 16) developed a right pneumothorax at $30 \mathrm{hr}$ of age and survived.

The control infants did not have respiratory distress syndrome. The eight full term control infants had Apgar scores greater than 6. Two of the seven prema ture control infants (nos. 9 and 12) had Apgar scores below 6 at $1 \mathrm{~min}$ of age. All control infants were clinically well during the period of study and on discharge from the hospital.

Oral and parenteral fluid intake are tabulated for each infant in Table I. The volume and type of feeding given were determined by the clinical team responsible for the care of each infant. Other than insuring that bicarbonate was administered by slow constant intravenous infusion, no attempt was made to standardize intake. When infants regurgitated, the volume was estimated by the nursing staff and subtracted from the previous feeding. Tluree infants witl RDS (nos. 18, 24 , and 25) never received oral feedings because of the severity of the disease. Nine of the 10 infants with RDS and 2 (nos. 12 and 13) of the 7 premature control infants were treated intravenously with $10 \%$ glucose and bicarbonate according to a previously described regimen [33]. One infant with RDS (no. 25) who died at $13 \mathrm{hr}$ of age and 2 premature control infants (nos. 9 and 11 ) were treated with $10 \%$ glucose and water without bicarbonate administered intravenously. Sodium bicarbonate, when given, was infused at rates of $0.13-0.41 \mathrm{mEq} / \mathrm{kg} / \mathrm{hr}$, and intravenous fluids at a rate of approximately $65 \mathrm{ml} / \mathrm{kg} / 24 \mathrm{hr}$.

During study periods all infants were nursed and fed in incubators [37] having a relative humidity of 90-100\%. Body temperature was maintained within the normal range $\left(36.5-37.5^{\circ}\right)$.

Oxygen was administered to infants with RDS in amounts necessary to relieve cyanosis. 
Table $I$. Birth weight, gestational age, and metabolic data

\begin{tabular}{|c|c|c|c|c|c|c|c|c|c|c|c|c|c|c|}
\hline \multirow{2}{*}{$\begin{array}{c}\text { Subject } \\
\text { no. }\end{array}$} & \multirow{2}{*}{$\begin{array}{l}\text { Birth } \\
\text { wt, g }\end{array}$} & \multirow{2}{*}{$\begin{array}{l}\text { Gestational } \\
\text { age, wk }\end{array}$} & \multicolumn{2}{|c|}{ Milk intake } & \multirow{2}{*}{$\begin{array}{c}\text { Glucose } \\
\text { water } \\
\text { intake }\end{array}$} & \multicolumn{3}{|c|}{$\begin{array}{l}\mathrm{NaHCO}_{3} \text { intake, } \\
\mathrm{mEq} / \mathrm{kg} / 24 \mathrm{hr}\end{array}$} & \multicolumn{3}{|c|}{$\begin{array}{l}\text { Daily blood }\left[\mathrm{H}^{+}\right] \\
\mu \mathrm{mEq} / \text { liter }\end{array}$} & \multicolumn{3}{|c|}{$\begin{array}{l}\text { Net acid excretion }{ }^{3} \\
\mathrm{mEq} / \mathrm{kg} / 24 \mathrm{hr}\end{array}$} \\
\hline & & & pro & $\mathrm{ml} / \mathrm{kg} / 72 \mathrm{hr}$ & & Day 1 & Day 2 & Day 3 & Day 1 & Day 2 & Day 3 & Day 1 & Day 2 & Day 3 \\
\hline \multicolumn{15}{|c|}{ Full term control infants } \\
\hline 1 & 3575 & Unknown & $\mathrm{C} 20$ & 366 & 22 & 0 & 0 & 0 & 44.0 & 43.6 & (d) & +0.26 & +0.61 & (d) \\
\hline 2 & 3080 & 40.5 & $\mathrm{C} 20$ & 534 & 95 & 0 & 0 & 0 & 43.7 & 45.3 & (d) & +0.39 & +1.45 & (d) \\
\hline 3 & 3620 & 39 & $\mathrm{C} 20$ & 277 & 21 & 0 & 0 & 0 & (d) & 41.5 & 39.2 & (d) & +2.03 & +1.58 \\
\hline 4 & 3340 & 41.5 & $\mathrm{C} 20$ & 385 & 17 & 0 & 0 & 0 & 48.2 & 43.4 & 41.3 & +0.54 & +1.72 & +2.76 \\
\hline 5 & 3090 & Unknown & Human & 362 & 16 & 0 & 0 & 0 & 40.5 & 42.0 & 42.2 & -0.01 & +0.59 & +0.58 \\
\hline 6 & 2960 & 40 & HMS20 & 317 & 31 & 0 & 0 & 0 & 43.6 & 40.3 & 41.8 & +0.35 & +0.56 & +1.39 \\
\hline 7 & 3960 & 41 & HMS30 & 277 & 17 & 0 & 0 & 0 & 44.8 & (d) & 41.0 & +0.58 & (d) & +0.52 \\
\hline 8 & 3960 & 41 & $\mathrm{C} 20$ & 331 & 19 & 0 & 0 & 0 & 45.1 & 43.0 & 43.7 & +0.37 & +1.19 & +1.28 \\
\hline Mean & 3448 & & & & & & & & 44.3 & 42.7 & 41.5 & +0.35 & +1.16 & +1.35 \\
\hline \multicolumn{15}{|c|}{ Premature control infants } \\
\hline 9 & 1220 & 28.5 & Human & 93 & 169 & 0 & 0 & 0 & 43.7 & 42.7 & 43.5 & -0.11 & 0.00 & +0.06 \\
\hline 10 & 1950 & 35.5 & $\mathrm{C} 20$ & 385 & 44 & 0 & 0 & 0 & 47.3 & 38.0 & 39.4 & +0.15 & +1.23 & +1.42 \\
\hline 11 & 1075 & 29 & HMS30 & 172 & 225 & 0 & 0 & 0 & 49.1 & 46.3 & 43.9 & 0.00 & +0.04 & -0.04 \\
\hline 12 & 1185 & 30 & HMS30 & 187 & 154 & 9.5 & 0 & 0 & 42.3 & 36.9 & 38.7 & -0.19 & +0.05 & -0.13 \\
\hline 13 & 1590 & 30.5 & Human & 98 & 242 & 1.8 & 0 & 0 & 46.1 & 37.4 & 42.2 & -0.41 & -0.49 & -0.13 \\
\hline 14 & 1605 & 32.5 & $\mathrm{C} 20$ & 425 & 66 & 0 & 0 & 0 & 40.8 & (d) & 44.8 & +0.11 & (d) & +1.45 \\
\hline 15 & 1680 & 32.5 & Human & 321 & 46 & 0 & 0 & 0 & 43.4 & (d) & 39.4 & +0.18 & (d) & +0.68 \\
\hline $\begin{array}{c}\text { Mean } \\
\text { 1nfants with }\end{array}$ & $\begin{array}{l}1472 \\
\text { RDS }\end{array}$ & & & & & & & & 44.7 & 40.3 & 41.7 & -0.04 & +0.17 & +0.47 \\
\hline $\begin{array}{l}\text { 1nfants with } \\
16\end{array}$ & $\begin{array}{l}\text { RDS } \\
1805\end{array}$ & 30.5 & $\mathrm{C} 18$ & 27 & 215 & 8.2 & 4.5 & 2.7 & 63.7 & 57.8 & 46.9 & -0.31 & -0.72 & -1.94 \\
\hline 17 & 2300 & 34 & $\mathrm{Cl} 8$ & 145 & 102 & 1.7 & 2.4 & 0.1 & 49.8 & 44.1 & 42.4 & +0.21 & +0.14 & +0.40 \\
\hline 18 & 3500 & 34.5 & NPO & 0 & $(86)^{\mathrm{a}}$ & 5.8 & $(3.2)^{\mathrm{a}}$ & (a) & 64.8 & 71.2 & (a) & +0.14 & -0.98 & (a) \\
\hline 19 & 1220 & 27 & Fuman & 110 & 247 & 0.8 & 0 & 0 & 45.2 & 44.0 & 50.8 & -0.35 & -0.41 & -0.20 \\
\hline 20 & 1290 & 29 & Human & 197 & 144 & 1.3 & 0 & 0 & 44.4 & 45.5 & 48.3 & +0.03 & -0.16 & +0.05 \\
\hline 21 & 1535 & 28 & $\mathrm{C} 23$ & 157 & 68 & 5.3 & 0 & 0 & 62.1 & 43.7 & 45.7 & +0.06 & 0.00 & -0.20 \\
\hline 22 & 1775 & 33.5 & $\mathrm{C} 20$ & 223 & 82 & 2.1 & 0 & 0 & 48.3 & 41.8 & 45.1 & +0.11 & -0.38 & +0.20 \\
\hline 23 & 2150 & Unknown & $\mathrm{C} 20$ & 331 & 70 & 1.3 & 0 & 0 & 51.7 & 45.8 & 45.3 & +0.33 & +1.01 & +1.73 \\
\hline 24 & 4710 & 37.5 & NPO & 0 & $(71)^{b}$ & 5.1 & $(3.6)^{\mathrm{b}}$ & (b) & 53.2 & 55.0 & (b) & +0.33 & +0.65 & (b) \\
\hline 25 & 1380 & 32 & NPO & 0 & $(41)^{c}$ & 0 & (c) & (c) & 87.8 & (c) & (c) & -0.50 & (c) & (c) \\
\hline Mcan & 2167 & & & & & & & & 57.1 & 49.9 & 46.4 & -0.01 & -0.09 & +0.01 \\
\hline
\end{tabular}

1 Type of milk feeding: $\mathrm{C} 18$, 行 diluted part skim evaporated cow's milk, $17.6 \mathrm{kcal} / \mathrm{oz} ; \mathrm{C} 20,2 / 3$ diluted whole evaporated cow's milk, $20 \mathrm{kcal} / \mathrm{oz}$; C23, 4/5 dilutcd whole evaporated cow's milk, $22.8 \mathrm{kcal} / \mathrm{oz}$; HMS20, human milk substitute (Similac), $20 \mathrm{kcal} / \mathrm{oz}$; FMS30, human milk substitute (Similac), $30 \mathrm{kcal} / \mathrm{oz}$.

2 Intravenous and per os.

$+:$ Net acid excretion; - : net base excretion.

(a) Death at $34 \mathrm{hr}$.

(b) Death at $33 \mathrm{hr}$

(c) Death at $12 \mathrm{hr}$.

(d) Urine collection grossly contaminated.

\section{Methods}

Using a Hepner-Lubchenco metabolic bed [14], urine was collected from each infant during the first $72 \mathrm{hr}$ of life. Each voiding was collected separately in small polyethylene bottles, accurately timed by means of an electrical signalling device, immediately capped, and refrigerated at $4^{\circ}$. At 24,48 , and $72 \mathrm{hr}$ of age, individual voidings were assembled into daily urine collections. Any individual voiding contaminated with stool was discarded, and its appropriate time period was subtracted from that of the daily urine collection. Each daily urine collection was mixed well and its volume was measured. It was then divided into aliquots of $5-30 \mathrm{ml}$ and frozen in tightly capped polyethylene bottles at $-30^{\circ}$ until analyzed. Because of stool contamination, six daily urine collections from six con- trol infants (no. 3 on day 1 ; nos. 7,14 , and 15 on day 2 ; nos. 1 and 2 on day 3) were not analyzed. Four daily urine collections from three infants with RDS (nos. 18, 24 , and 25) were not obtained because the infants died before completion of the study.

Since urine was collected under conditions allowing exposure to air, the anerobic urine $\mathrm{pH}$ was derived from the mean capillary blood carbon dioxide tension $\left(\mathrm{PCO}_{2}\right)$ and the $\mathrm{pH} / \log \mathrm{PCO}_{2}$ buffer line for each daily urine collection. The $\mathrm{pH}$ was measured potentiometrically at $38^{\circ}$ after equilibration of urine samples with two known $\mathrm{CO}_{2}$ mixtures. The $\mathrm{pH} / \mathrm{log}$ $\mathrm{PCO}_{2}$ buffer line was plotted from these two paired $\mathrm{pH}$ and $\mathrm{PCO}_{2}$ values. The $\mathrm{pH}$ on the buffer line corresponding to the mean arterialized capillary blood $\mathrm{PCO}_{2}$ is the derived anerobic pH. Figure 1 demon- 


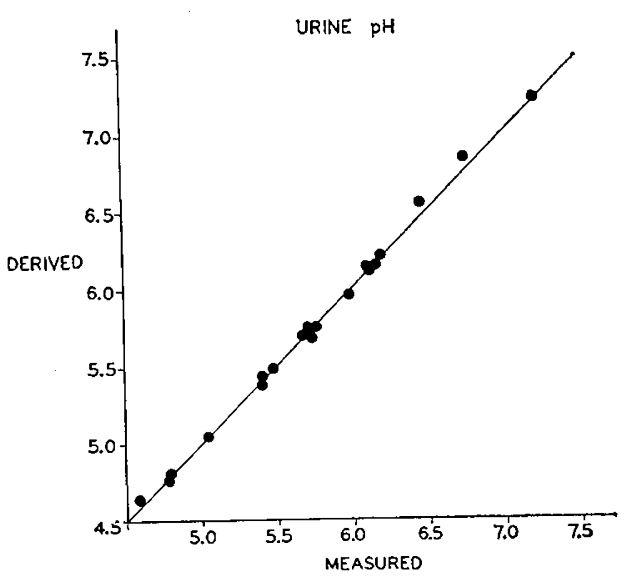

Fig. 1. Correlation between the $\mathrm{pH}$ measured on anerobically collected urine and the derived "anerobic" $\mathrm{pH}$ determined on aerobically collected urine using the method described in the text.

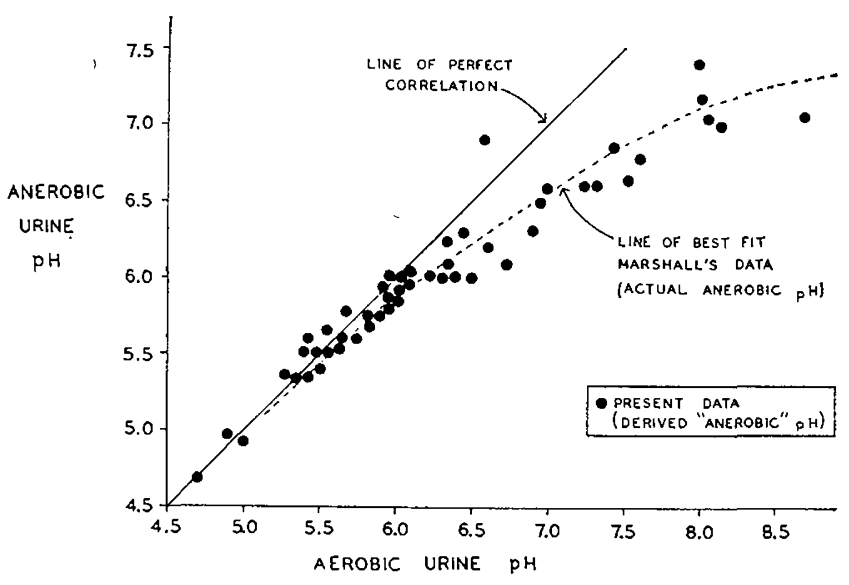

Fig. 2. Relation between the derived "anerobic" $\mathrm{pH}$ and the $\mathrm{pH}$ of aerobic urine in 51 24-hr urine specimens from 12 newborn infants. The dotted line is that which best fits Marshall's data [20] from single voidings in adults comparing the $\mathrm{pH}$ of anerobically collected urine with that which was subsequently exposed to air.

strates that the derived $\mathrm{pH}$ of single voidings from 19 infants having capillary blood $\mathrm{PCO}_{2}$ values ranging from 20 to $61 \mathrm{~mm} \mathrm{Hg}$ closely approximates the $\mathrm{pH}$ of an anerobically collected sample from the same voiding. Anerobic samples were collected in $100-\mu 1$ capillary tubes that were filled directly from the urinary stream and immediately sealed with plasticine. The $\mathrm{pH}$ of the anerobic samples was measured potentiometrically at $38^{\circ}$ within $15 \mathrm{~min}$ of collection. Figure 2 illustrates the alkaline shift from the derived anerobic $\mathrm{pH}$ that occurred when the carbon dioxide tension of 51 24-hr urine collections from 12 infants was equilibrated with that of air. Also illustrated is the line of best fit for the alkaline shift found by Marshall [19] in single voidings collected anerobically from adults (Fig. 2). The close correlation observed between these data from newborn 24-hr urine collections and Marshall's data from adult single voidings is evidence that the $\mathrm{pH}$ derived on 24-hr collections by the above technique closely approximates that $\mathrm{pH}$ which would have been measured if the urine had not been exposed to air. This technique, established for single voidings, was therefore applied to 24-hr urine collections; the derived anerobic $\mathrm{pH}$ was calculated from the urine $\mathrm{pH} / \log \mathrm{PCO}_{2}$ buffer plot and the mean capillary blood $\mathrm{PCO}_{2}$. Acid and base concentrations were measured on each daily urine collection. "Titratable acid minus bicarbonate" concentration, which remains unchanged when urine is exposed to air, was measured titrimetrically at room temperature as the excess alkali required, after removal of bicarbonate by acidification, to reach an end point $\mathrm{pH}$ of 7.4 [1]. Urinary bicarbonate and titratable acid concentrations were measured titrimetrically at room temperature. The derived anerobic urine $\mathrm{pH}$ and $\mathrm{pH} 7.4$ were used as end points for titration of bicarbonate and titratable acid, respectively. Results of the titrimetric procedures were not corrected for variations in urinary ionic strength [26] and are subject to error resulting from the differences between body temperature and the temperature at which the titration was performed [36]. Since the phosphate concentration of newborn urine is low, the maximum theoretical cumulative error in "titratable acid minus bicarbonate" concentration due to urinary ionic strength and to temperature may be as great at 1.5 $\mathrm{mEq} /$ liter $[26,36]$. Urinary titratable acid and bicarbonate measurements are, in addition, subject to that error due to differences between the derived and the true anerobic $\mathrm{pH}$.

Urinary ammonium concentration was measured by the microdiffusion method of Seligson and Seligson [29]. Net acid concentration, which is not altered by exposure of urine to air, was calculated as the sum of "titratable acid minus bicarbonate" and ammonium concentrations.

Mean daily body weight was determined from body weights measured twice daily. Urine flow was proportionately converted to volume per $24 \mathrm{hr}$. Using mean daily body weights, urine flow was expressed as milliliters per kilogram body weight per $24 \mathrm{hr}$ and served as a basis for calculation of excretion rates.

Carbon dioxide tension $\left(\mathrm{PCO}_{2}\right)$, hydrogen ion, and actual bicarbonate concentrations were measured by the micro-Astrup technique [3] on blood obtained by heel prick after the foot had been immersed for 5 min 
in a water bath at $42^{\circ}$ [10]. Measurements were made at $38^{\circ}$ and were not corrected for actual body temperature. The $\mathrm{PCO}_{2}$ values in blood and bicarbonate concentrations were not corrected for hemoglobin desaturation. Acid-base values in blood were measured at the beginning and end of each daily urine collection in all infants and more frequently in infants who were acidotic. A daily value represents the weighted mean of the individual determinations obtained during the corresponding urine collection period; i.e., weighted for the time period represented by the individual values: for example, the weighted mean for values $\mathrm{A}, \mathrm{B}$, and $\mathrm{C}$ obtained at 0,8 , and $24 \mathrm{hr}$, respectively, in a 24-hr study is calculated as:

$$
\frac{[8 \mathrm{hr} \times(\mathrm{A}+\mathrm{B}) / 2]+[16 \mathrm{hr} \times(\mathrm{B}+\mathrm{C}) / 2]}{24 \mathrm{hr}}
$$

Because of small numbers of infants in each group, statistical analyses were not applied to these data.

\section{Results}

\section{Acid-Base Balance in Blood}

Daily acid-base values in blood during the first 3 days of life are presented on a nomogram in Figure 3. Each value corresponds to a day on which a urine collection was obtained. Isobars for $\mathbf{P C O}_{2}$ were calcu- lated from the Henderson equation [13]. In addition, hydrogen ion concentrations in blood for each day studied are presented in Table I.

Full term and premature control infants had a mild metabolic acidemia which was compensated by mild hypocapnia so that daily hydrogen ion concentrations in blood were not greater than $49.1 \mu \mathrm{mEq} /$ liter $(\mathrm{pH}<$ 7.31). Infants with RDS had higher levels of $\mathrm{PCO}_{2}$ in blood resulting in higher hydrogen ion and bicarbonate concentrations than those found in control infants. Among infants with RDS, high bicarbonate concentrations were associated with high hydrogen ion concentrations in blood. Bicarbonate concentration was greater than $24 \mathrm{mEq} /$ liter in 10 of the 26 observations on infants with RDS; 6 were associated with hydrogen ion concentrations greater than $50 \mu \mathrm{mEq} /$ liter $(\mathrm{pH}<$ 7.30). Nine of 10 infants with RDS who received intravenous sodium bicarbonate remained acidemic in relation to control infants. No infant with RDS ever became alkalemic, the single lowest measured concentration of hydrogen ion in blood being $37.2 \mu \mathrm{mEq} /$ liter $(\mathrm{pH}=$ 7.43).

\section{Urine Hydrogen Ion Concentration}

The hydrogen ion concentration and $\mathrm{pH}$ in urine during days 1, 2, and 3 of life are presented in Figure

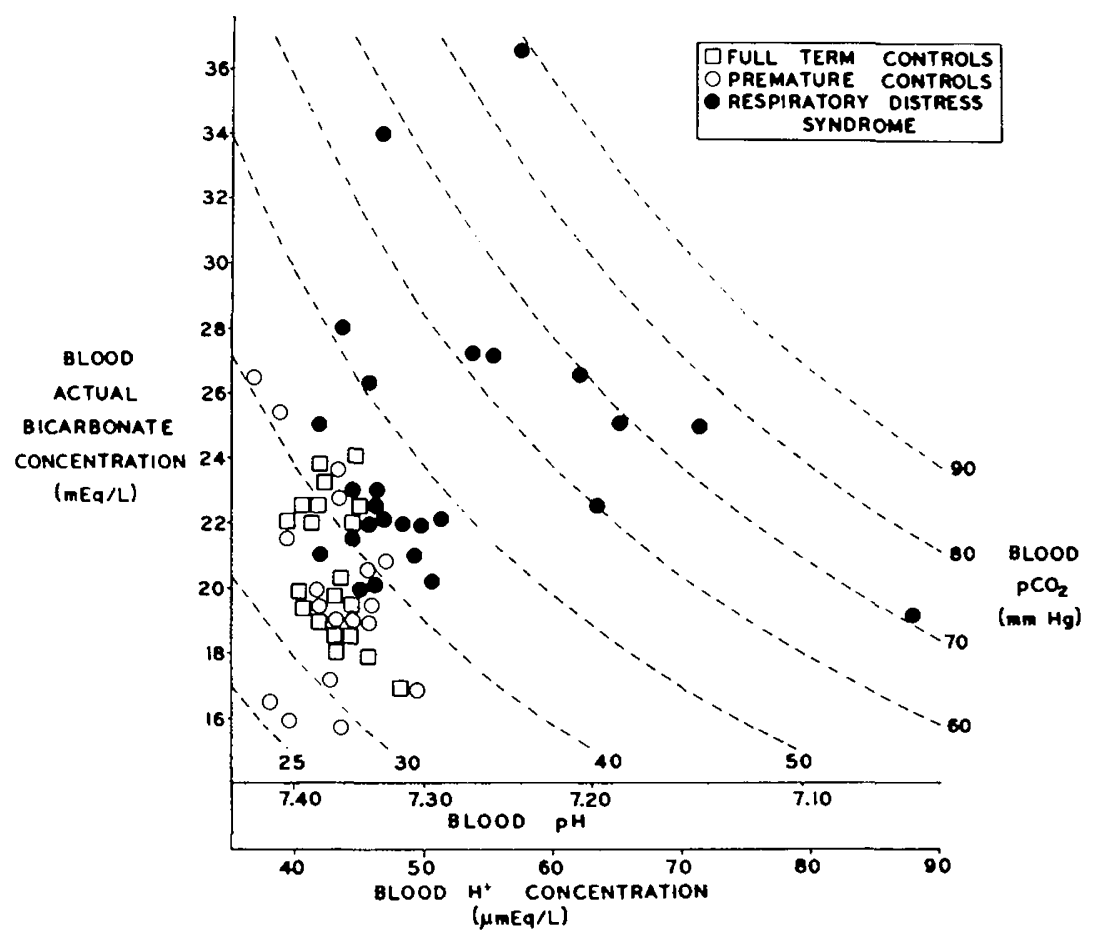

Fig. 3. Daily hydrogen ion, bicarbonate, and $\mathrm{PCO}_{2}$ values in blood in full term control infants ( $\square$ ), premature control infants (O), and infants with RDS (-) during the first 3 days of life. Each value corresponds to a day on which a urine collection was obtained. 


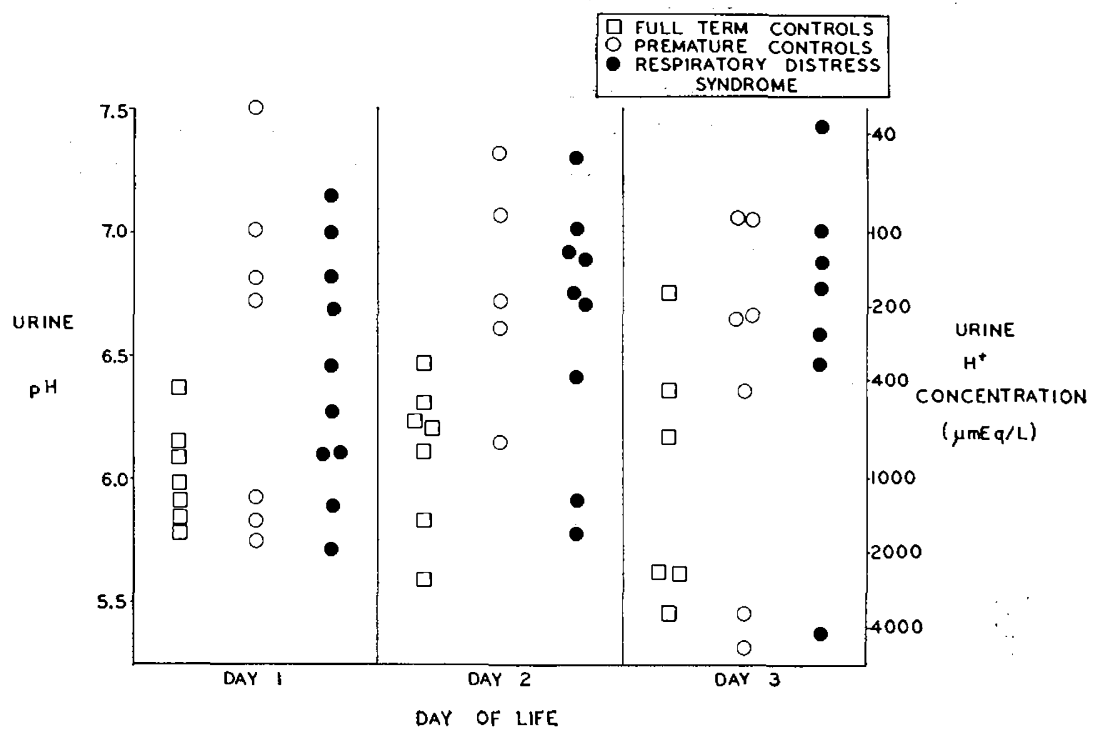

Fig. 4. Hydrogen ion concentration (plotted on a log scale) of daily urine collections obtained on each of the first 3 days of life.

4. Premature control infants and infants with RDS excreted urine having similar concentrations of hydrogen ion, but alkaline in comparison with that excreted by full term control infants.

\section{Urinary Acid-Base Concentrations}

Urinary titratable acid, ammonium, bicarbonate, and net acid concentrations are presented in relation

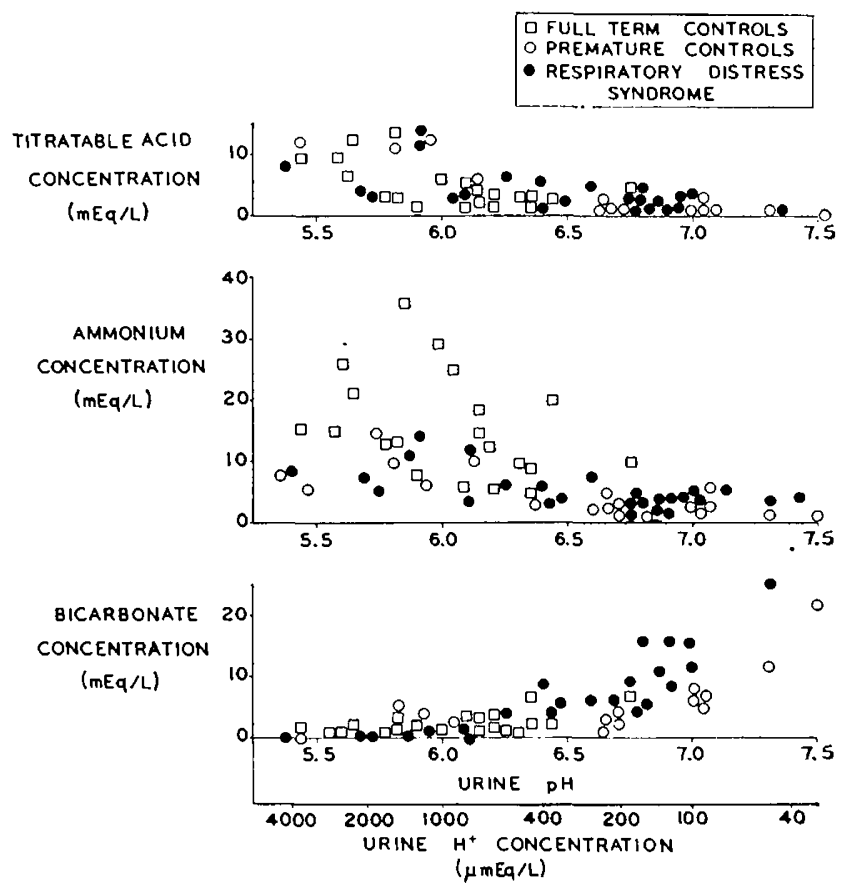

Fig. 5. Relation between hydrogen ion concentration in urine and concentration of titratable acid, ammonium, and bicarbonate in urine during the first 3 days of life. to hydrogen ion concentrations in urine (Figs. 5 and 6). Titratable acid and ammonium concentrations varied directly, and bicarbonate concentration inversely, with hydrogen ion concentration in urine. Net acid (titratable acid + ammonium - bicarbonate) concentration, therefore, varied directly with hydrogen ion concentration. Urine having hydrogen ion concentrations greater than $450 \mu \mathrm{mEq} /$ liter $(\mathrm{pH}<6.35)$ always contained net acid while urine having concentrations

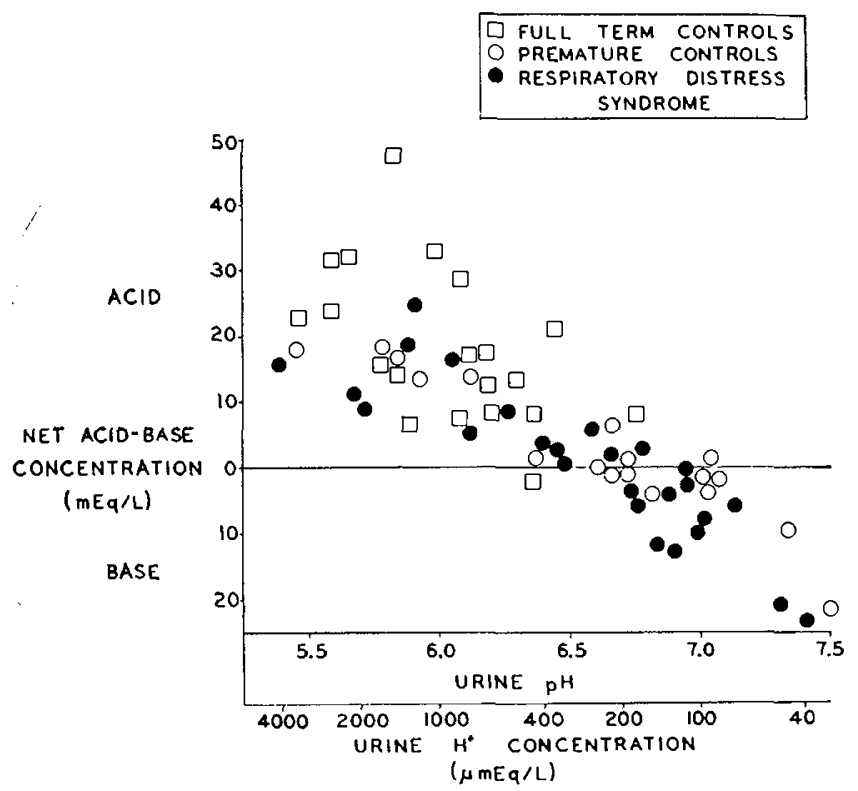

Fig. 6. Relation between hydrogen ion concentration in urine and concentration of net acid-base in urine during the first 3 days of life. 
less than $85 \mu \mathrm{mEq} /$ liter $(\mathrm{pH}>7.07)$ always contained net base.

Correlations between titratable acid and hydrogen ion concentrations in urine were similar for all three groups of infants. When hydrogen ion concentration was greater than $400 \mu \mathrm{mEq} /$ liter $(\mathrm{pH}<6.40)$, ammonium concentrations were appreciably greater in full term control infants than in either premature control infants or infants with RDS. When the hydrogen ion concentration in urine was less than $400 \mu \mathrm{mEq} /$ liter ( $\mathrm{pH}>6.40)$, bicarbonate concentration was higher in infants with RDS than in urine of premature control infants. Because of these differences, at high hydrogen ion concentrations, full term control infants excreted urine having higher net acid concentration than did premature control infants and infants with RDS. At low hydrogen ion concentrations, infants with RDS excreted urine having higher net base concentration than did premature control infants.

\section{Contribution of Urine Phosphorus to Urine Titratable Acid Concentration}

Figure 7 presents the relation between urine phosphorus and titratable acid concentrations. The dotted line extending from the origin is the expected titratable acid concentration if all urine phosphorus and only urine phosphorus were utilized as titratable acid; i.e., $\left[\mathrm{HPO}_{4}=\right] /\left[\mathrm{H}_{2} \mathrm{PO}_{4}^{-}\right]=4 / 1$, present at normal plasma hydrogen ion concentration, changed to $\left[\mathrm{HPO}_{4}=\right] /\left[\mathrm{H}_{2} \mathrm{PO}_{4}^{-}\right]=1 / 99$, present in acidified urine (pH 4.8) (calculated as: $\mathrm{mg} / 100 \mathrm{ml} \mathrm{P} \times$ mole fraction of $\mathrm{P}$ acidified/atomic wt $\mathrm{P}=[(\mathrm{mg} / 100 \mathrm{ml} \mathrm{P} \times 0.79) /$ 31] $\times 10 \mathrm{~mm} /$ liter). During the first 3 days of life, there was no correlation between urine phosphorus and titratable acid concentrations. High concentrations of titratable acid occurred in relation to low concentrations of phosphorus. Conversely, high concentrations of phosphorus occurred in relation to low concentrations of titratable acid.

\section{Urinary Net Acid-Base Excretion}

The values for excretion of net acid or net base for each infant on days 1, 2, and 3 of life are presented in Table $\mathrm{I}$ and Figure 8. The mean net acid-base excretion in urine for each group of infants on each day of life is presented in Table I. On each day, seven of the eight full term control infants always excreted 0.26 $\mathrm{mEq} / \mathrm{kg} / 24 \mathrm{hr}$ or more of net acid in urine. None of the premature control infants excreted this amount on day 1 and only three of five premature control infants who did not receive bicarbonate achieved this level on day 3 . In both control groups mean net acid excretion

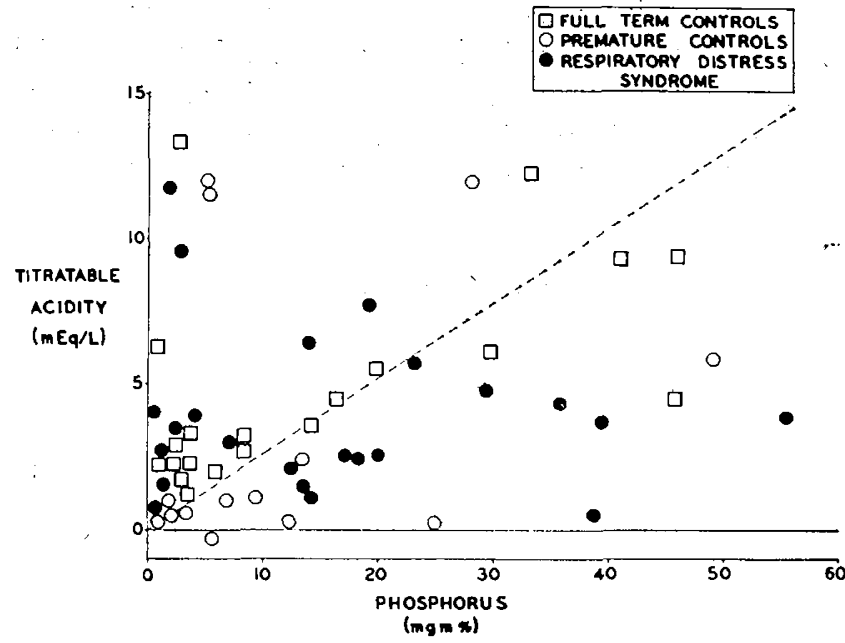

Fig. 7. Relation between phosphorus concentration and titratable acid concentration in urine during the first 3 days of life. The dotted line represents the expected titratable acid concentration if all phosphorus and only phosphorus in urine were titrated.

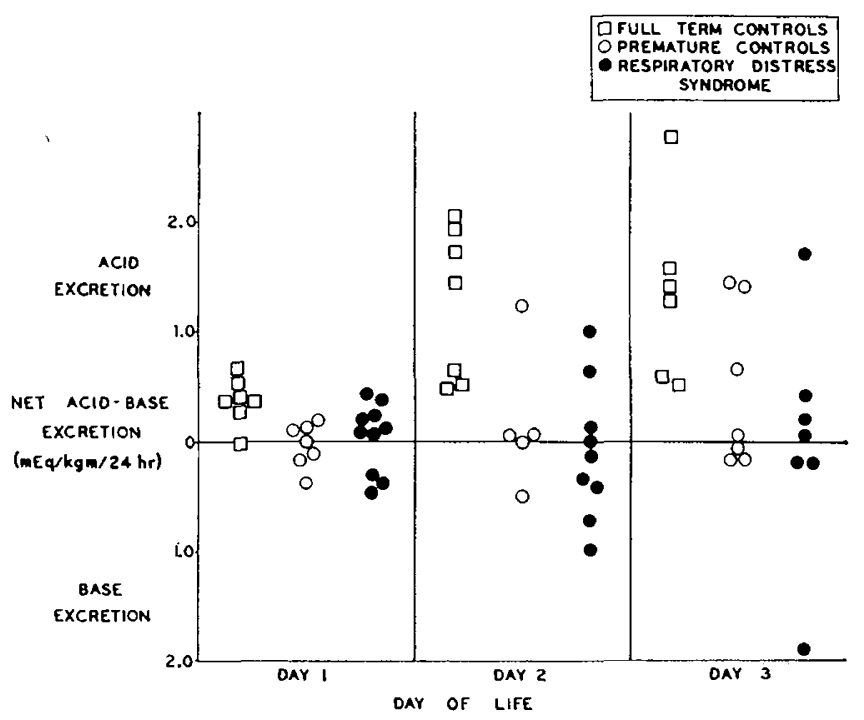

Fig. 8. Net acid-base excretion in urine on each of the first 3 days of life.

in urine increased with each day of advancing postnatal age. On each day, mean net acid excretion was greater in full term control infants than in either premature control infants or infants with RDS.

Infants with RDS were similar to premature control infants in excreting net acid in 14 of the 26 daily urine collections. In contrast with premature control infants, however, there was no apparent tendency for net acid excretion in urine to increase with advancing postnatal age in infants with RDS.

During days 2 and 3 of life, all nonacidemic full 
term control infants excreted more than $0.50 \mathrm{mEq} / \mathrm{kg} /$ $24 \mathrm{hr}$ of net acid in urine. In contrast, only three of the seven nonacidemic premature control infants and two of the nine infants with RDS, even though acidemic, attained this level of urinary acid excretion.

\section{Relation between Acid-Base Balance in Blood and Net Acid-Base Excretion in Urine}

Figure 9 presents the relation between the degree of acidemia and net acid excretion in urine during the

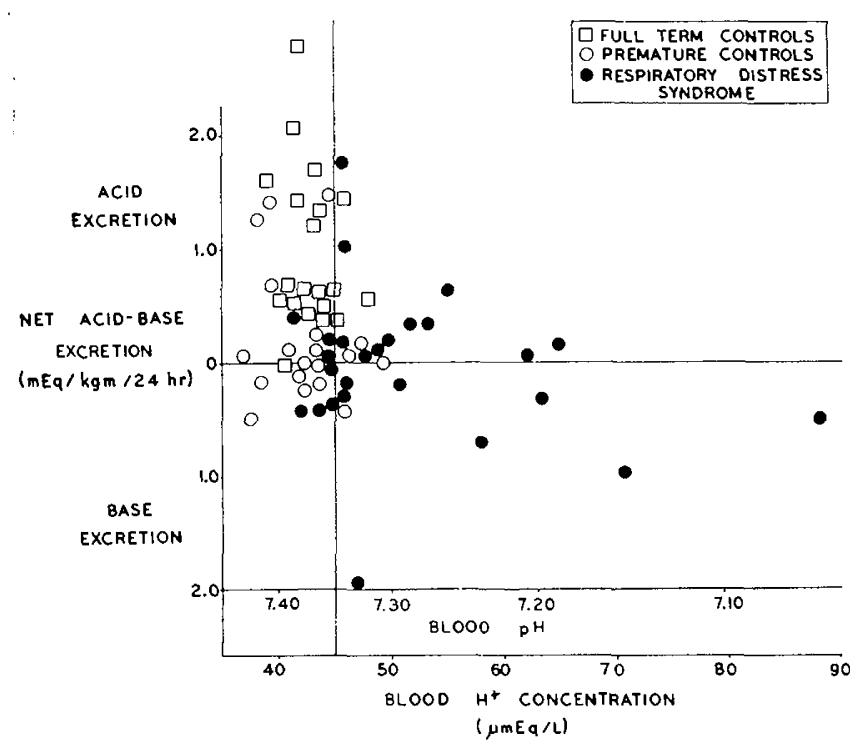

Fig. 9. Relation between hydrogen ion concentration in blood and net acid-base excretion in urine during the first 3 days of life.

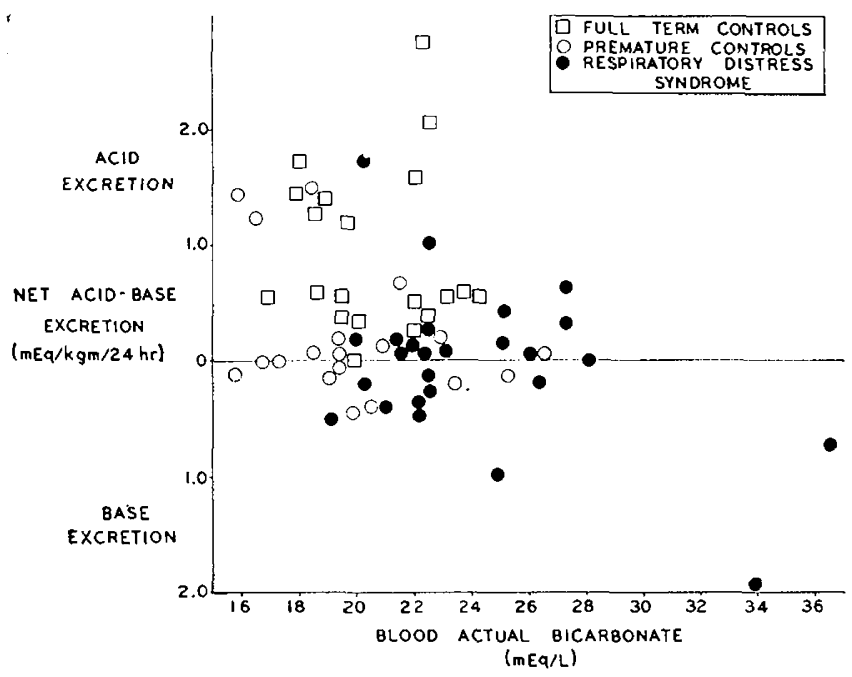

Fig. 10. Relation between bicarbonate concentration in blood and net acid-base excretion in urine during the first 3 days of life. first 3 days of life. Only one full term control infant excreted net base; his hydrogen ion concentration in blood was $40.5 \mu \mathrm{mEq} /$ liter $(\mathrm{pH}=7.39$ ). Premature control infants excreted either net acid or net base in association with normal hydrogen ion concentrations in blood. Infants with RDS did not excrete net acid when they were severely acidemic.

Net acid-base excretion in urine is presented in relation to bicarbonate concentration in blood in Figure 10 and to $\mathrm{PCO}_{2}$ values in blood in Figure 11. In fullterm and premature control infants no correlation was observed between net acid excretion in urine and bicarbonate concentration or $\mathrm{PCO}_{2}$ values in blood. Some acidemic infants with RDS, however, excreted large amounts of net base in relation to both high bicarbonate concentrations and high $\mathrm{PCO}_{2}$ levels in blood.

\section{Discussion}

During the first 3 days of life, the range of hydrogen ion concentrations in urine in normal full term infants has been found to be similar to that in adults $[20,21$, 30]. Despite adequate hydrogen ion concentrations in urine, however, McCance and Widdowson [21] showed that full term infants, during the first 2 days of life, excreted less acid per unit body weight in urine than adults. This apparent deficiency in acid excretion was related to decreased excretion of phosphate which is utilized as buffer for titratable acid [21]. Because of this decreased titratable acid excretion, when compared with adult values, a greater proportion of total acid was excreted as ammonium by infants than that excreted by adults [21].

On day 7 of life, Hatemi and McCance [12] demonstrated that in response to an acute acid load, acid

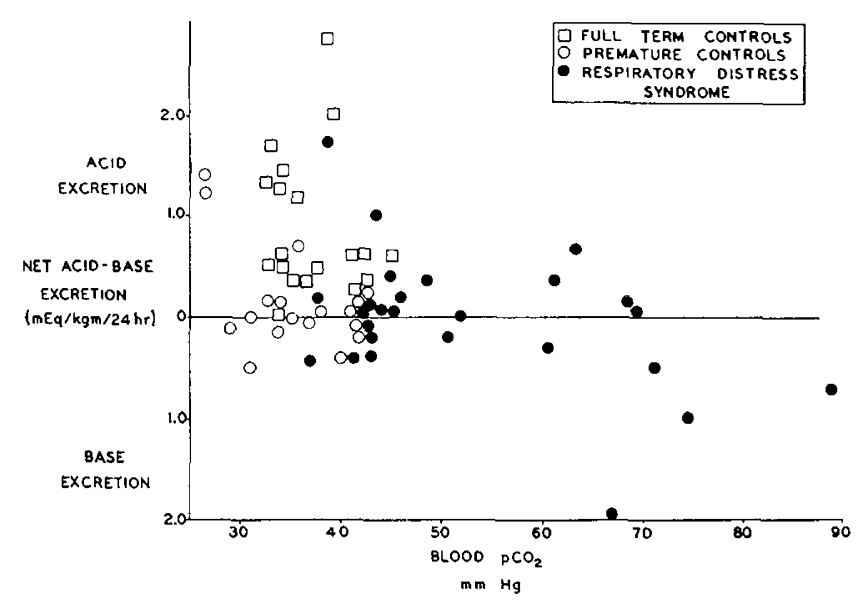

Fig. 11. Relation between $\mathrm{PCO}_{2}$ in blood and net acid-base excretion in urine during the first 3 days of life. 
excretion in urine per unit of body surface area in full term infants was decreased compared with that in adults. This decreased capacity for acid excretion in newborn infants was associated with decreased hydrogen ion concentration and decreased titratable acid excretion in urine, in comparison with that in adults. The decrease in titratable acid excretion was again related to low phosphate excretion in urine and was improved by prior phosphate loading [12].

Edelmann et al. [6] have demonstrated a lowered renal bicarbonate threshold in infants 1.5-12 months of age in comparison with that in normal adults and suggested that this was due to functional heterogeneity of nephrons.

Acid excretion in urine has not previously been evaluated in premature or low birth weight infants during week 1 of life. The acute renal response to an acid load in low birth weight infants between 26 and 49 days of age was shown by Ruben et al. [24] to be similar to that in adults. Three low birth weight infants, 11-45 days of age, were found by Gordon et al. [11] to excrete less urinary ammonium than 3 full term infants, 51-122 days of age. Rubin et al. [25] found that 4 smaller low birth weight infants, 9 days of age, excreted less urinary ammonium than 3 larger low birth weight infants, 11-14 days of age. Tudvad et al. [31] showed that the maximum tubular reabsorption rate of bicarbonate in 12 low birth weight infants, 8-37 days of age, was $25-26 \mathrm{mEq} /$ liter and concluded that acidosis associated with prematurity was not due to defective bicarbonate reabsorption, although the renal threshhold for bicarbonate excretion was not evaluated.

Dietary acid load varies with the amount and type of milk formula [9, 15-17]. The effect of diet on acidbase balance and on acid excretion was assumed to be minimal during the first 3 days of life and small in comparison with the changes associated with RDS.

The present investigation demonstrated that some infants with RDS not only failed to respond to acidemia by increasing acid excretion in urine but often excreted net base, thereby exacerbating the existing acidemia (Figs. 8 and 9).

Slow, constant infusion intravenous bicarbonate therapy in 9 of the 10 infants with RDS may have caused the increased excretion of net base observed in these infants. Four of the 10 infants remained acidemic throughout the study; however, none ever became alkalemic or hyperbicarbonatemic in relation to the steady state adjustment of blood bicarbonate concentration to graded degrees of chronic hypercapnia defined in dogs by Schwartz et al. [27], in man by van Ypersele de Strihou et al. [35], and in children with cystic fibrosis of the pancreas by Engel et al. [8]. Moreover, 1 infant with RDS (no. 25) did not receive bicarbonate therapy. This infant became severely acidemic (blood $[\mathrm{H}+]=87.8 \mu \mathrm{mEq} /$ liter) and excreted net base $(0.50 \mathrm{mEq} / \mathrm{kg} / 24 \mathrm{hr})$ comparable to the amounts excreted by infants with RDS who received slow infusions of bicarbonate. Expansion of the extracellular fluid space due to intravenous therapy may have decreased the tubular reabsorption of sodium and therefore bicarbonate; however, total oral and parenteral fluid intake differed very little in the three groups (Table I). It seems unlikely, therefore, that the slow constant intravenous infusion of bicarbonate solution accounted for the net base excretion observed in acidemic infants with RDS.

Nonacidemic full term control infants excreted more acid on each day of life than nonacidemic premature control infants and acidemic infants with RDS (Fig. 8). In addition, both full term and premature control infants increased acid excretion with each day of advancing postnatal age (Fig. 8). Since RDS is a disease associated with low gestational age and occurs during the first 3 days of postnatal life, the apparently decreased capacity for acid excretion seen in these infants could well have been related to age rather than to the disease process itself. Data relating gestational and postnatal age to the renal capacity for acid excretion will be published [2].

Hydrogen ion concentrations in urine of infants with RDS were similar to those found in premature control infants (Fig. 4); however, infants with RDS differed from premature control infants in the following ways: $(I)$ by having higher blood $\mathrm{PCO}_{2}$, hydrogen ion, and bicarbonate concentrations (Fig. 3); (2) by excreting higher bicarbonate concentrations in urine (Fig. 5) and, therefore, higher net base concentrations at low urine hydrogen ion concentration (Fig. 6); and (3) by failing to increase net acid excretion with advancing postnatal age (Fig. 8). Infants with RDS, therefore, did not respond appropriately to acidemia by excreting more net acid than nonacidemic premature control infants (Figs. 8 and 9).

Premature control infants and infants with RDS excreted urine having lower hydrogen ion concentrations than full term control infants (Fig. 4). The failure of acidemic infants with RDS to create a high urine/ plasma hydrogen ion concentration gradient suggests a deficiency in the renal tubular secretion of hydrogen ion $[4,7,22]$. Improvement of this function with gesta- 
tional age in control infants suggests the maturation of a partially deficient enzyme system such as carbonic anhydrase $[4,28]$.

Compared with the excretory capabilities of adults, and in agreement with results found in infants studied by McCance et al. $[12,21]$, the infants presented here were limited in their ability to excrete urine titratable acid by low phosphate excretion (Fig. 7). Infants with severe RDS, however, who had relatively higher phosphate concentrations in urine due to catabolism, did not acidify this urinary buffer to form titratable acid (Fig. 7). The apparent deficiency in tubular secretion of hydrogen ion, therefore, superseded the apparent deficiency in phosphate excretion.

When hydrogen ion concentrations in urine were greater than $400 \mu \mathrm{mEq} /$ liter $(\mathrm{pH}<6.40$ ), acidemic infants with RDS and nonacidemic premature control infants excreted urine having a lower ammonium concentration than nonacidemic full term control infants (Fig. 5). Ammonium concentration in urine is determined by renal tubular ammonia production and by "diffusion trapping" of ammonia in tubular urine having a high hydrogen ion concentration [18, 22]. At higher hydrogen ion concentrations, therefore, ammonium concentration reflects renal tubular ammonia production [18]. The failure of infants of low gestational age to excrete ammonium at high hydrogen ion concentrations suggests a deficiency in renal tubular ammonia production. The apparent increase with greater gestational age suggests the maturation of a partially deficient renal ammonia-producing enzyme system, such as glutaminase I [18].

Higher bicarbonate concentration in blood due to $\mathrm{CO}_{2}$ retention results in the delivery of a greater filtered load of bicarbonate to the renal tubule for reabsorption [7, 22]. In examining the response of mongrel dogs to atmospheres containing 11-13\% $\mathrm{CO}_{2}$, Polak et al. [23] found a fall in hydrogen ion concentration in urine, a small increase in titratable acid excretion on day 1 followed by a decrease, and an increase in bicarbonate excretion. The generation of bicarbonate in compensation for respiratory acidemia was achieved in these dogs by large increases in ammonium excretion, which exceeded the decrease in titratable acid and increase in bicarbonate excretion. Infants with RDS did not respond to respiratory acidemia and to consequent higher concentration of filtered bicarbonate by change in hydrogen ion concentration and titratable acid excretion in urine (Figs. 4 and 5). Assuming similar glomerular filtration rates, a greater filtered load of bicarbonate would have been reabsorbed and therefore more hydrogen ions secreted by infants with RDS in comparison with that secreted by premature control infants. Infants with RDS, however, did not increase urine/plasma hydrogen ion concentration gradient beyond that produced by nonacidemic premature infants and, therefore, at higher $\mathrm{PCO}_{2}$ values formed urine containing higher bicarbonate concentration. This resulted in greater bicarbonate excretion and was similar to the response seen in dogs exposed to $\mathrm{CO}_{2}$ [23].

Infants with RDS, because they were prematurely born, did not show the physiologic increase in ammonium excretion that was found in dogs exposed to $\mathrm{CO}_{2}$ [23] and therefore compensated neither for the increased bicarbonate excretion nor for the accumulation of hydrogen ion due to respiratory acidemia. The deficiency of ammonium excretion, therefore, resulted in the failure of bicarbonate generation needed to restore the body buffer ratios and in some acidemic infants resulted in net bicarbonate excretion that worsened the existing acidemia.

\section{References and Notes}

1. Albright, F., Bauer, W., and Aub, J. C.: Studies of calcium and phosphorus metabolism. IV. The effect of the parathyroid hormone. J. Clin. Invest., 7 : 139 (1929).

2. Allen, A. C., AND Usher, R.: Gestational and postnatal growth of renal capacity for acid excretion. To be published.

3. Astrup, P., Jørgensen, K., Siggard-Andersen, O., and Engel, K.: The acid-base metabolism. A new approach. Lancet $i$ : 1035 (1960).

4. BERLINER, R. W.: Renal secretion of potassium and hydrogen ions. Fed. Proc., 11: 695 (1952).

5. Boston, R. W., Geller, F., and Smith, C. A.: Arterial blood gas tensions and acid-base balance in the management of the respiratory distress syndrome. J. Pediat., 68: 74 (1966).

6. Edelmann, C. M., JR., Soriano, J. R., Boichis, H., Gruskin, A. B., AND AcostA, M. I.: Renal bicarbonate reabsorption and hydrogen ion excretion in normal infants. J. Clin. Invest., 46: 1309 (1967).

7. Elkinton, J. R.: Renal acidosis. Amer. J. Med., 29: 165 (1960).

8. Engel, K., Dell, R. B., Rahill, W. J., Denning, C. R., AND WINTERS, R. W.: Quantitative studies of acid-base displacement in respiratory acidosis. Unpublished manuscript cited in Winters, R. N.: Studies of acid-base disturbances. Pediatrics, 39: 700 (1967).

9. Fomon, S. J., Harris, D. M., and Jensen, R. L.: Acidification of the urine by infants fed human milk and whole cow's milk. Pediatrics, 23: 113 (1959).

10. Gandy, G., Grann, L., Cunningham, N., Adamsons, K., JR., AND James, L. S.: The validity of $\mathrm{pH}$ and $\mathrm{PCO}_{2}$ measurements in capillary samples in sick and healthy newborn infants. Pediatrics, 34: 192 (1964).

11. Gordon, H. H., McNamara, H., and Benjamin, H. R.: The response of young infants to ingestion of ammonium chloride. Pediatrics, 2: 2£0 (1948).

12. Hatemi, N., and McCance, R. A.: Renal aspects of acid- 
base control in the newly born: III. Response to acidifying drugs. Acta Paediat. Scand., 50: 603 (1961).

13. Henderson, L. J.: The theory of neutrality regulation in the animal organism. Amer. J. Physiol., 21: 427 (1908).

14. Hepner, R., and Lubchrnco, L. O.: A method of continuous urine and stool collection in young infants. Pediatrics, 26: $828(1960)$.

15. HunT, J. N.: The influence of dictary sulfur on the urinary output of acid in man. Clin. Sci., 15: 119 (1956).

16. Lemann, J., JR., and Relman, A. S.: The relation of sulfur metabolism to acid-base balance and electrolyte excretion: The effects of DL-methionine in normal man. J. Clin. Invest., $38: 2215$ (1959).

17. Lennon, E. J., Lemann, J., Jr., and Relman, A. S.: The effects of phosphoproteins on acid balance in normal subjects. J. Clin. Invest., 41: 637 (1962).

18. Lotspeich, W. D.: Metabolic Aspects of Renal Function, p. 89 (Charles C Thomas, Springfield, Ill., 1959).

19. Marshall, E. K., JR.: The effects of loss of carbon dioxidc on the hydrogen ion concentration of urine. J. Biol. Chem., 51: 3 (1922).

20. MCCANCE, R. A., AND von Finck, M. A.: The titratable acidity, $\mathrm{pH}$, ammonia and phosphates in the urine of very young infants. Arch. Dis. Childhood, 22: 200 (1947).

21. MCCANCE, R. A., AND Widdowson, E. M.: Renal aspects of acid-base control in the newly born. I. Natural development. Acta Paediat. Scand., 49: 409 (1960).

22. Pitts, R. F.: Physiology of the Kidney and Body Fluids, p. 163 (Yearbook Medical Publishers, Chicago, 1963).

23. Polak, A., Haynie, G. D., Hays, R. M., nNd Schwartz, W. B.: Effects of chronic hypercapnia on electrolyte and acid-base eçuilibrium. I. Adaptation. J. Clin. Invest., 40: 1223 (1961).

24. Ruben, B. L., Calcagno, P. L., Rubin, M. I., and WernTRAUB, D. H.: Renal defense response to induced acidosis in premature infants. Amer. J. Dis. Child., 92: 513 (1956).

25. Rubin, M. I., Calcagno, P. I., and Ruben, B. L.: Renal excretion of hydrogen ions: A defense against acidosis in premature infants. J. Pediat., 59: 848 (1961).

26. SChWARtz, W. B., BANk, N., and Cutler, R. W. P. The influence of urinary ionic strength on phosphate $\mathrm{pK}_{2}^{\prime}$ and the determination of titratable acid. J. Clin. Invest., 38: 347 (1959).

¿7. Schwartz, W. B., Bracketr, N. C., JR., and Cohen, J. J.: The response of extracellular hydrogen ion concentration to graded degrees of hypercapnia: The physiologic linnits of the defense of pH. J. Clin. Invest., 44: 291 (1965).
28. Schwartz, W. B., Falbriard, A., And Relman, A. S.: An analysis of bicarbonate reabsorption during partial inhibition of carbonic anhydrase. J. Clin. Invest., 37: 744 (1958).

29. Seligson, D., and Selrgson, H.: A micro-diffusion method for the determination of nitrogen liberated as ammonia. J. Lab. Clin. Med., 38: 324 (1951).

30. Thomson, J.: Observation on the urine of the newborn infant. Arch Dis. Childhood, 19: 169 (1944).

31. Tudvad, F., McNamara, H., and Barnetr, H. L.: Renal response of premature infants to the administration of bicarbonate and potassium. Pediatrics, 13: 4 (1954).

32. Usher, R.: The metabolic changes in respiratory distress syndrome of prematurity seen as a failure of somatic compensations for asphyxia. In: Ciba Foundation Symposium on Somatic Stability in the Newly Born, p. 92 (Ciba Foundation, New York, 1961).

33. Usher, R.: The respiratory distress syndrome of prematurity. Pediat. Clin. N. Amer., 8: 525 (1961).

34. Usher, R., MCLeAN, F., AND ScotT, K. E.: Judgment of fetal age. II. Clinical significance of gestational age and an objective method for its assessment. Pediat. Clin. N. Amer., 13: 835 (1966).

35. van Ypersele de Strihou, C., Brasseur, L., and DeConinck, J.: The 'carbon dioxide response curve' for chronic hypercapnia in man. New Engl. J. Mcd., 275: 119 (1966).

36. Wesson, L. G., JR.: Effect of temperature change on the pH of human urine. J. Appl. Physiol., 5: 619 (1952-53).

37. Isolette, Air-Shields, Inc., Hatboro, Penna.

38. All procedures were performed in accordance with the provisions set forth in the Declaration of Helsinki.

39. The authors are greatly indebted to Dr. John B. Dossetor for his encouragement and advice, and to Francis McLean, R.N., for her most faithful assistance in the collection of specimens and calculation of data. We are most grateful to the nursing staff of the Premature Nursery for their care and effort in the accurate collection of urine; to Benoit Beauchemin, Kenneth Lee, and Anthony Chau for technical assistance; and to Lois Coons, R.N., for the preparation of figures.

40. Supported by Canada Health Grant no. 604-13-88.

41. Requests for reprints should be addressed to: Alexander C. Allen, M.D., Department of Pediatrics, Magee-Womens Hospital, Forbes Avenue and Halket Street, Pittsburgh, $\mathrm{Pa} .15213$ (USA).

42. Accepted for publication October 15, 1970. 